\title{
Atomic mechanism of the bainite transformation
}

\author{
H. K. D. H. Bhadeshia ${ }^{1}$ \\ ${ }^{1}$ University of Cambridge, Materials Science and Metallurgy,U.K., hkdb@cam.ac.uk
}

\begin{abstract}
I have on previous occasions shown how we can be surprised and delighted by new discoveries in steels, which at the same time may be useful. However, my focus in this lecture is purely on some basic science so that a well-founded understanding of mechanisms can lead to ever greater advances. The composite structure that is known colloquially as bainite is arguably the most interesting of all of the essential microstructures that occur in steels, where the manner in which atoms move is seminal to the design of steels. Therefore, I take the liberty to indulge myself and talk only of theory on this occasion.
\end{abstract}

\section{Keywords}

Atomic mechanism, bainite, shape deformation, local equilibrium, thermodynamic, dissipations

\section{Introduction}

Bainite is not a phase, rather, it can be an aggregate of phases consisting predominantly of platelets of ferrite but with a sprinkling of minority phases such as carbides or residual austenite [Davenport 1930], [Bhadeshia 2015b]. It is lovely structure that has advantages including the fact that it can be generated uniformly in huge components such as steam turbines [Colbeck, Rait 1952], or can be used microscopically as a surface treatment to enhance tribological properties [Zhang et al. 2008]. The structure is amenable to careful control - for example, its scale can be regulated from hundreds of micrometres to tens of nanometres [Bhadeshia, Honeycombe 2017]. Such variations are reflected in properties, emphasising the versatility of the structure. There are cases where the structure has such a high energy absorbing capacity that the Charpy toughness cannot in fact be measured because the energy absorbed is off the upper limit of the scale at subzero temperatures [Zhu et al. 2016].

A number of the industrial advances that have been made in recent years have relied on the theoretical understanding of the bainite transformation. The theory therefore is not simply fodder for academic debate. Any completely satisfactory theory of a phase transformation must explain in quantitative detail the known set of observations. It should also be able to venture into previously unknown domains so that experiments can be done to verify its ability to generalise. Some of its predictions may lead to previously unknown consequences, which is when it becomes thrilling.

But first, it is important to set aside any discussion about whether or not there is the diffusion of atoms during the transformation. In the next few paragraphs I describe a disarmingly simple way to distinguish changes in crystal structure that are accomplished by the homogeneous deformation of the lattice, as opposed to those that occur by a higgledy-piggledy movement of atoms. All that is required is to monitor the transformation of austenite that has been deformed beyond a critical plastic strain $\varepsilon$.

Fig. 1 illustrates two kinds of interfaces consisting of dislocation arrays between the parent and product crystals. The glissile interface is able to translate without diffusion because the Burgers vectors of the interfacial dislocations lie outside of the plane of the boundary. The corresponding dislocations in the sessile interface would need to climb for the boundary to move, with diffusion occurring over a distance comparable to the scale of the transformation product [Bhadeshia 1985]. A distinguishing characteristic of these two kinds of interfaces is that obstacles (defects) 
in the path of a glissile interface hinder its motion. A point is reached where it cannot advance because the driving force for the translation of the interface is less than the pinning force due to obstacles. Dislocations introduced by plastic deformation of the parent phase are potent obstacles to glissile interfaces. At this critical strain within the parent phase, transformation is entirely suppressed. Figs 1b,c show the dramatic suppression of the bainite transformation in deformed austenite [Shipway, Bhadeshia 1995]. The critical strain $\varepsilon$ is defined by balancing the force due to the chemical free energy change $(b \Delta G)$ against the term on the right hand side that opposes the movement of the interfacial array of dislocations - the details including nomenclature, are available elsewhere [Chatterjee et al. 2006], suffice it to say that quantitative predictions are possible:

$$
b \Delta G=\frac{1}{8 \pi(1-v)} G b^{\frac{3}{2}} \sqrt{\frac{\varepsilon}{L}}+\tau s b
$$

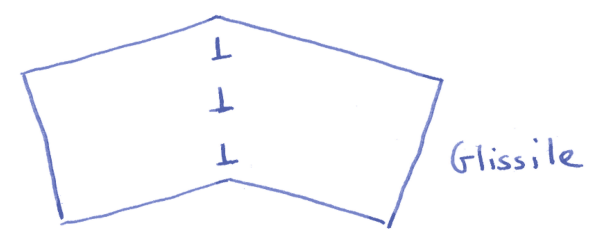

(a)

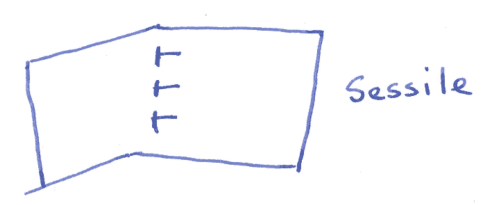

(b)
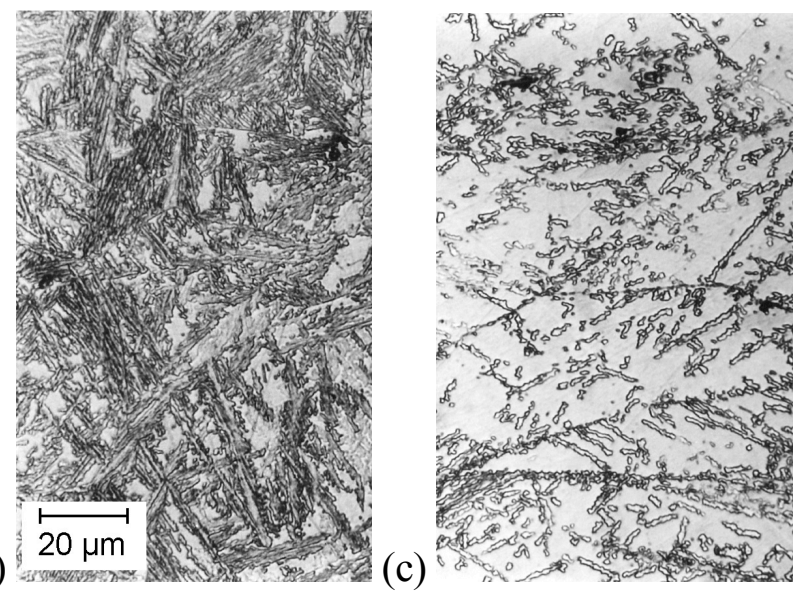

Figure 1: (a) Glissile \& sessile interfaces consisting of dislocation arrays. (b) Bainite in undeformed austenite. (c) Transformation suppressed in deformed austenite [Shipway, Bhadeshia 1995].

In contrast, (reconstructive) transformations that rely on diffusion are actually accelerated if the parent phase is plastically deformed - indeed, this is the whole basis of the thermomechanical treatment of billions of tonnes of steel into ferrite plus pearlite microstructures. The test described here is conclusive, does not require expensive equipment and yet unveils information on atomic mechanisms.

There is no mechanism by which plastic deformation can retard reconstructive transformation. Likewise, only displacive transformations can be mechanically stabilised.

\section{Shape deformation}

It has been self-evident, ever since the first report that the shape of the austenite is altered by the formation of bainitic ferrite [Ko, Cottrell 1952], that the transformation is displacive with no possibility of the diffusion of substitutional atoms including iron. Indeed, bainite can grow at temperatures where the calculated diffusion distance of iron is an inconceivable $10^{-17} \mathrm{~m}$ over the time scale of the experiment [Bhadeshia 2015b]. The observed displacements show that the change in lattice is caused by an orderly transfer of atoms across the interface. There is a wonderful analogy that emphasises this point. Mechanical twins and annealing twins in metals 
have precisely the same crystallographic orientation, but the former is an actual deformation that is a simple shear on the twin plane, whereas the latter essentially is a growth accident which leaves the shape of the object unchanged. Annealing twins can form only in circumstances where atoms can diffuse over distances comparable with the scale of their structure. There are no restrictions in principle to the lowest temperature at which mechanical twins can be induced by applying an appropriate stimulus.

\begin{tabular}{|l|l|l|l|}
\hline Item & Structure change? & Volume change? & Shape deformation? \\
\hline Annealing twin & None & None & None \\
Mechanical twin & None & None & Shear strain $(1 / \sqrt{ } 2)$ \\
Bainite & fcc to bcc or bct & Yes & Shear $(\sim 0.26)$, dilatation $(\sim 0.02)$ \\
Martensite & fcc to bcc or bct & Yes & Shear $(\sim 0.26)$, dilatation $(\sim 0.03)$ \\
\hline
\end{tabular}

Table 1: Distinguishing characteristics of twins and transformations. fcc, bcc and bet represent the face-centred cubic, body-centred cubic and body-centred tetragonal structures of iron.

The detailed nature of the shape deformation is illustrated in Fig. 2. Such a deformation is known as an invariant-plane strain where the horizontal habit-plane is neither distorted nor rotated. The shear component $s$ of the strain is parallel to that plane and the dilatation $\delta$ normal to it. The arrows indicate that the displacements become larger with distance normal to the invariant-plane. When the crystal transforms surrounded by others, large displacements become intolerable so to minimise the elastic strain energy per unit volume $\left(G_{\text {strain }}\right)$ the plate adopts a lens-like (lenticular) shape with a sharp tip so that the displacement at the tip itself becomes negligible [Christian 1958]. The maximum thickness that the plate can achieve then depends on a balance between the elastic strain energy and the chemical driving force for transformation. It is not surprising then that mechanical twins, martensite, and bainite grow as thin objects that are plates in three dimensions.

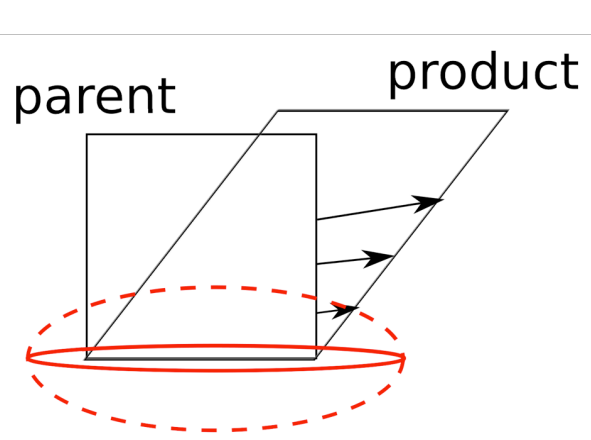

$$
\begin{aligned}
G_{\text {strain }} & \approx \frac{c}{r} \mu\left(s^{2}+\delta^{2}\right) \\
c & =\text { plate thickness } \\
r & =\text { plate length } \\
\mu & =\text { austenite shear modulus } \\
s & =\text { shear strain } \\
\delta & =\text { dilatational strain }
\end{aligned}
$$

Figure 2: The shape deformation determines the lenticular shape of bainite plates. The fat plate outlined with dashed lines is less favoured when compared with the thinner one because the magnitude of the displacements increases with thickness even though the strain (displacement divided by height) is identical at all points in the vertical direction.

There is a caveat to this discussion. It has been assumed that the shape deformation is elastically accommodated by the surrounding austenite. Often, at the elevated temperatures where bainite grows, the austenite is mechanically weak. The strains listed in Table 1 are huge when compared with a typical elastic strain in structural engineering, at just $10^{-3}$. It is possible then, that the austenite adjacent to the bainite plate relaxes by plastic deformation.

Fig. 3a shows an atomic force microscope image of a single-crystal of austenite that was polished flat and then transformed into bainite platelets [Swallow, Bhadeshia 1996]. The shear deformation caused by each platelet is obvious, identified in one case with the arrow marked ' $a$ '. 
It is noteworthy, as explained above, that the platelets have sharp tips. The region marked ' $b$ ' on the other hand represents austenite that has relaxed by plastic deformation because the transformation strain is greater than can be sustained elastically by the austenite. This creates intense arrays of dislocations in the vicinity of the transformation interface, which then is stopped in its tracks. Therefore, the platelet stops growing before it has encountered a hard obstacle such as an austenite grain boundary. This phenomenon is known as mechanical stabilisation [Machlin, Cohen 1951] and is absolute proof of a displacive transformation mechanism [Bhadeshia 2015b]. It becomes necessary for another platelet to 'nucleate' at the tip of the original one for the transformation to progress. As a consequence, the macroscopic sheaf (collection of platelets) forms as illustrated in Fig. 3b. Thus, the plastic relaxation of the austenite leads to a huge refinement of structure when compared with martensite plates whose size depends essentially on the geometrical partitioning of the parent austenite.
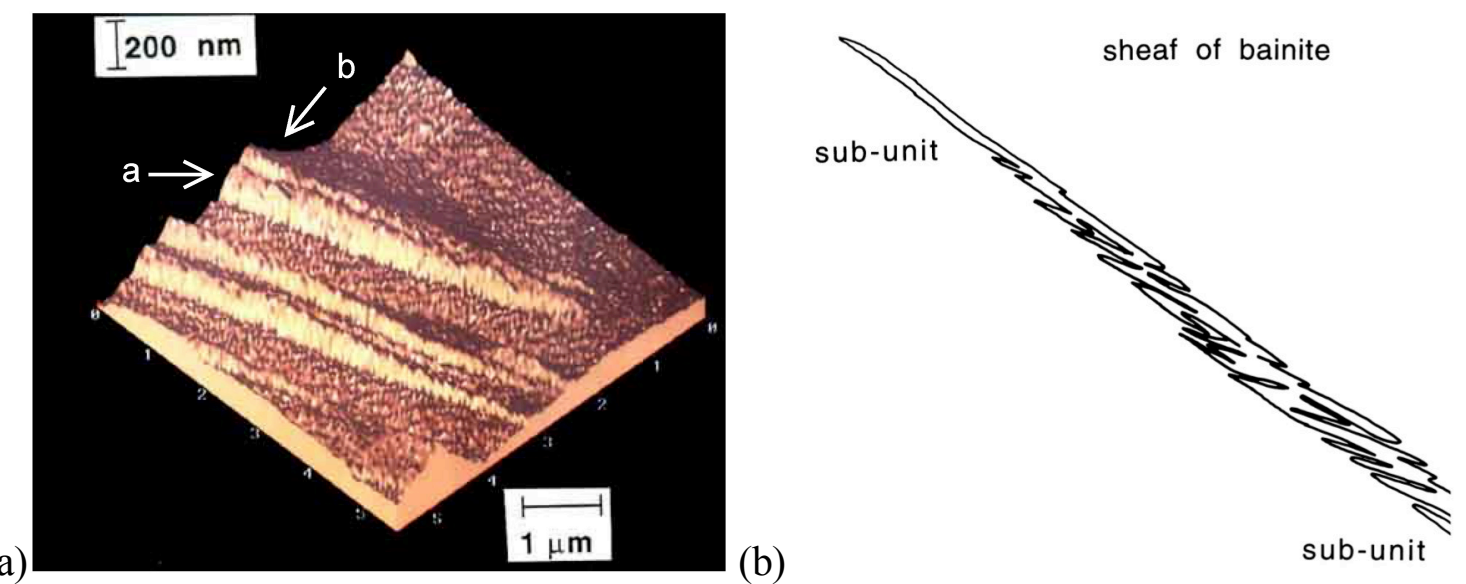

Figure 3: (a) Atomic force microscope image showing the displacements caused by bainite sub-units [Swallow, Bhadeshia 1996]. (b) Schematic illustration of the sub-units of bainite that make up a sheaf.

\section{The interface}

We have seen that the growth of bainite is accompanied by a change in the shape of the transformed region, a change that reflects a coordinated motion of atoms. This deformation is not favoured from a thermodynamic point of view because it causes strains; the associated strain energy reduces the driving force for transformation. Such a concept does not sit comfortably with the idea that there is diffusion or equilibrium. The meaning of diffusion is the intermingling of atoms, which in the presence of chemical potential gradients represents a flow of atoms, albeit in the solid state, a flow that should lead to a reduction in free energy. Such fluidity would not permit the development of the shape deformation but rather, an approach towards equilibrium. The fact that the deformation is observed is testimony to the displacive mechanism of the phase change that conveniently is neglected in other interpretations.

Bainite, like martensite, is thermodynamically a first order transformation [Ehrenfest 1933]. This means that the product and parent phases can co-exist, separated at a sharp interface. There are restrictions on the character of such a boundary because it must be able to move without diffusion. The structure of the boundary consists of two periodic features, atomic height steps that accomplish the change in crystal structures and dislocations that help to mitigate the longrange strain fields of these steps.

The steps are referred to as coherency dislocations [Olson, Cohen 1979] - they can glide or climb without diffusion and have a Burgers vector that is not a lattice vector because they accomplish transformation. This is illustrated in Fig. 4, with the step highlighted by the multi-shaded atoms at the interface. The atomic-height step has a dislocation character but there is no extra halfplane, just a tolerable distortion, which means that it can both glide and if necessary, climb 
without requiring diffusion. This is important because there usually is a change in density when one crystal structure is transformed into another. In summary, the coherency dislocations are those that accomplish the lattice change. However, having just coherency dislocations in the interface would result in long-range strain fields surrounding the transformed particle. The strain field is mitigated by anti-coherency dislocations that have Burgers vectors which are lattice vectors - their motion does not lead to transformation. They too must be glissile for bainitic or martensitic transformation, so their Burgers vectors must lie outside of the plane of the interface, or be screw dislocations. There are other restrictions that ensure a glissile character, described elsewhere in detail [Christian 2003, Bhadeshia 2017].

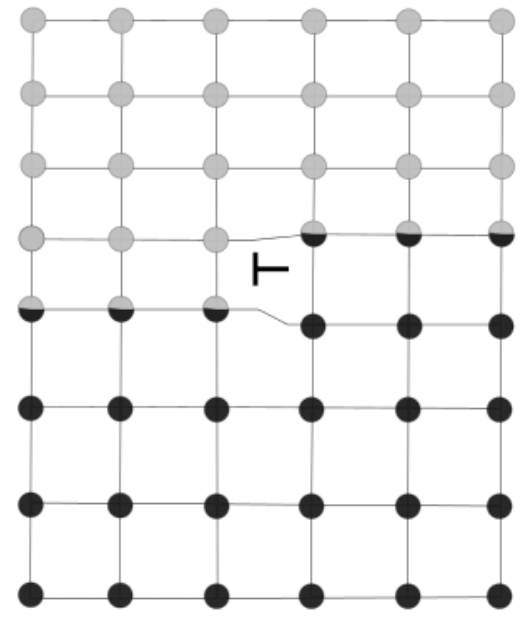

\section{coherency dislocation}
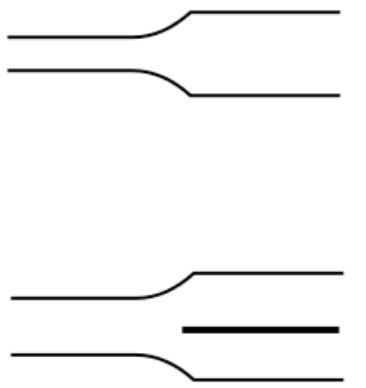

anti-coherency dislocation

Figure 4: A coherency dislocation that can climb conservatively while accomplishing lattice transformation. Adapted from [Olson, Cohen 1979]. The inset at the right is the representation of the coherency dislocation in a manner analogous to ordinary dislocations that have extra half-planes.

The Burgers vector content crossing a vector $\mathbf{p}$ in the interface (Fig. 5, OP) can be determined from the closure failure of a Burgers circuit [Bilby 1955], [Frank 1950], [Christian 2003]. The closed circuit AOBP in Fig. 5a spans the two different crystals. If a deformation (A S A) is now applied to convert one of the crystals into the other (reference crystal), then the closure failure $\mathrm{P}^{\prime} \mathrm{P}$ (Fig. 5b) represents the required Burgers vector content $\mathbf{b}_{\mathrm{t}}$ which can then be de-convoluted into individual dislocations to define the possible structure of the interface.

$$
\left[\mathrm{A} ; \mathbf{b}_{\mathrm{t}}\right]=\left\{\mathbf{I}-(\mathrm{A} \mathrm{S} \mathrm{A})^{-1}\right\}[\mathrm{A} ; \mathbf{p}]
$$
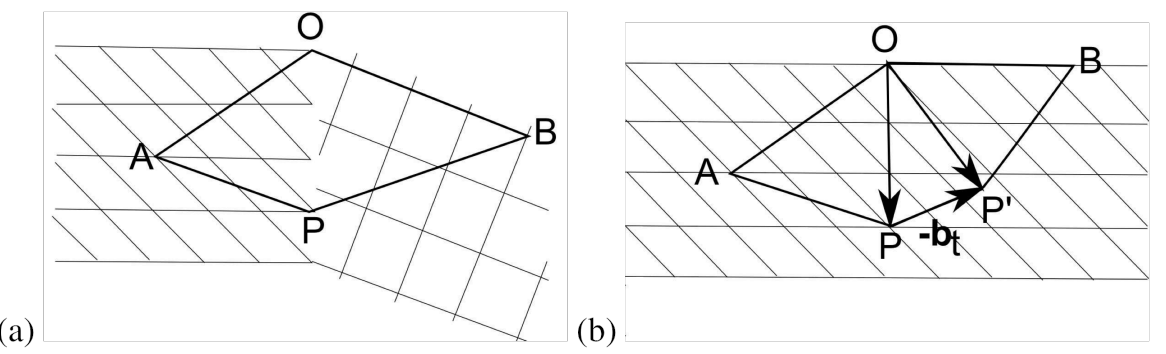

Figure 5: (a) Burgers circuit drawn across an interface between two different crystal structures. (b) One of the structures is deformed into the other to discover the closure failure that defines the Burgers vector content crossing a vector $(\mathrm{OP})$ in the interface. In the equation at the top, I represents the $3 \times 3$ identity matrix, (A S A) the homogeneous deformation that converts the assembly of crystals into a single reference-crystal with basis symbol ' $\mathrm{A}$ ' and $\mathbf{b}_{\mathrm{t}}=\mathrm{P}^{\prime} \mathrm{P}$ is the total Burgers vector content crossing a vector $\mathbf{p}=\mathrm{OP}$ in the interface. $\mathbf{b}_{\mathrm{t}}$ can then be attributed to individual defects in the interface. 
In summary, the structure of the bainite-austenite interface can be concluded to be glissile because its translation causes a particular deformation that can happen only if the atoms move in unison, rather like the performance of a carefully choreographed dance-troupe, as opposed to the pedetic motion associated with diffusion.

\section{Width of the interface}

Why should we worry about the width of the bainite-austenite interface? There are three essential reasons: (i) mathematical models exist which make unjustified assumptions about the width in order to make the algorithms work; (ii) high spatial-resolution experiments are now possible so that any local chemical composition can be characterised and compared with expectations based on the totality of evidence; (iii) there are difficulties with theories that apply conventional thinking to diffusion problems where steep concentration gradients exist.

The first issue is particularly prevalent in phase field models of bainite where the parent, product and interface are all represented in terms of an order parameter; the interface is therefore diffuse [Song et al. 2011], [Ramazani et al. 2013], [Arif, Qin 2013], [Arif, Qin 2014]. Both the definition of how the free energy density varies across the boundary, and the assumption of particular systematic gradients within the diffuse interface are arbitrary. High resolution transmission electron microscopy has shown that the bainite-austenite interface is in reality sharp, less than 1 $\mathrm{nm}$ in thickness [Kajiwara 1999, Kajiwara 2003, Ogawa:2006]. The treatment of the strain energy due to the shape deformation is either absent [Song et al. 2011], [Ramazani et al. 2013] or has been implemented incorrectly with shear occurring in all directions within the habit plane [Arif, Qin 2013], [Arif, Qin 2014]. When the shape deformation is neglected, the plate shape is generated by an arbitrary anisotropy of interfacial energy; this procedure amounts to image generation rather than a physical representation. I think it is reasonable to conclude that no new knowledge has emerged from the application of phase field methods to bainite [Bhadeshia 2015b].

The second issue marked (ii) concerns the availability of instruments, in particular of the field ion microscope/atom probe, and of course, high-resolution transmission electron microscopy. The latter gives a direct observation of interfacial width whereas the former has difficulties in the precise location of the interface due to effects described elsewhere [Bhadeshia 2015a]. Two conclusions can nevertheless be reached from the vast number of experiments that have been conducted using the atom-probe. The first is that there is absolutely no partitioning of substitutional solutes during the growth of bainite; this immediately invalidates any notions that the transformation to bainite could be occurring by a negligible partitioning local equilibrium mechanism (NPLE) [Coates 1972], [Coates 1973] in which growth occurs with very little redistribution of solutes but with local equilibrium maintained at the interface where a concentration spike occurs in the parent phase. The magnitude of this spike would ensure that the chemical potentials of the elements are identical in the $\alpha$ and $\gamma$.

Bainite forms at low temperatures so the width of these spikes has long been recognised as being unphysical [Coates 1972], [Coates 1973], often reaching dimensions far less than the size of atoms. Software such as DICTRA $\mathbb{C}$ [Borgenstam et al. 2000] allow these calculations to be conducted routinely, but it is not appreciated that there is a cost involved in the development of sharp concentration profiles [Bhadeshia 2016].

The free energy per atom $\left(g_{i h}\right)$ of a heterogeneous solid solution is given by [Hilliard 1970]:

$$
g_{i h}=\int\left[g\{\bar{c}\}+v_{\mathrm{a}}^{3} \kappa(\nabla c)^{2}\right] d V
$$

where the first term on the right represents the corresponding free energy per atom of a homogeneous solution of the average concentration, and the second term depends on the 
magnitude of the gradient in concentration $(\nabla c)^{2}$ and opposes the formation of steep gradients, with $\kappa$ being a gradient energy coefficient.

Fig. 6 shows why the NPLE mechanism is not physical when the concentration gradients are sufficiently steep - essentially, the gradient energy moderates the concentration profile to large widths, making the extent of partitioning greater and the growth rate slower. It is not surprising, therefore, that there are no experimental data [reviewed in Goune 2015] that confirm the existence of the sharp concentration spikes predicted theoretically in domains where the transformation is supposed to occur by the NPLE mode. This applies not just to bainite but allotriomorphic ferrite.

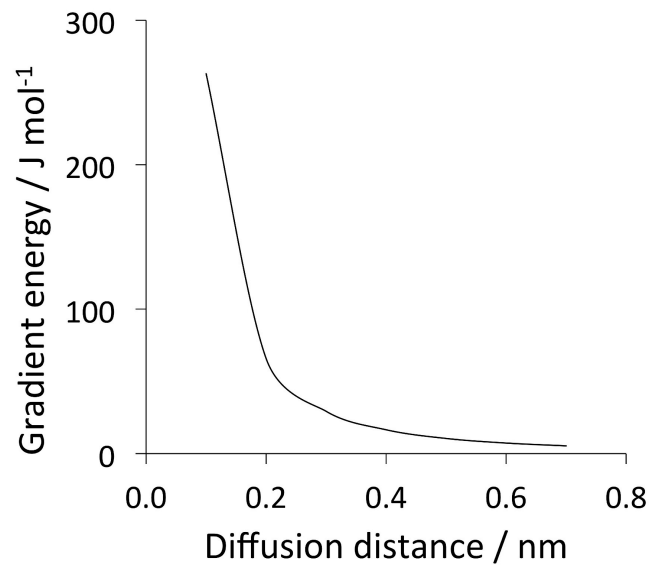

Figure 6: Estimate of the penalty on free energy due to the gradient of concentration in the austenite ahead of the $\alpha / \gamma$ interface [Bhadeshia 2016]. The diffusion distance refers to the width of the concentration spike at the interface.

It is noted that given the atom probe data, and the fact that steep gradients of concentration are costly in terms of free energy, any explanation of kinetics based on substitutional solute gradients existing within or without the interface are not real [Bhadeshia 1983]. All models that rely on dissipations due to such diffusion are also invalidated [Bhadeshia 2015b].

\section{Carbon}

The fact that bainite grows without any diffusion, not even that of carbon, has been reviewed [Bhadeshia 2015b] so will not be discussed here. The salient points are as follows:

- The growth rate when measured at sufficient resolution is orders of magnitude faster than expected on the basis of paraequilibrium, carbon diffusion-controlled lengthening of platelets [Bhadeshia 1984].

- In circumstances where the austenite retains its carbon, the reaction stops when the chemical composition is such that diffusionless growth is thermodynamically impossible [Bhadeshia, Edmonds 1980].

- The carbides that precipitate inside bainitic ferrite follow exactly the same orientation relationships and metastable precipitation sequences as during the tempering of martensite [Bhadeshia 2015b].

- Large concentrations of carbon have been observed in solid solution within the bainitic ferrite, far greater than permitted by equilibrium between cubic ferrite and austenite [Caballero et al. 2011], [Caballero et al. 2012], Caballero et al. 2014].

- When excess carbon in retained in solution, the ferrite lattice has been shown to be bodycentred tetragonal [Smith et al. 2013]. 


\section{Summary}

The accumulated evidence proves that bainite is nothing but martensite that may be tempered immediately after transformation. There are differences because the driving force available for bainite is smaller than for martensite. So although the nucleation mechanism for bainite, like martensite, involves the dissociation of dislocations, unlike martensite, it is required that carbon partitions during those early stages of genesis. The nucleus then evolves into diffusionless growth [Bhadeshia 2015b]. Secondly, the combination of the low driving force and weakness of the austenite at the temperatures where bainite typically forms, induces mechanical stabilisation that leads to a dramatic refinement of the structure. As a result, the platelets of bainite can be much finer than those of martensite.

It is important not to consider the bainite transformation in isolation. Table 2 outlines the characteristics of all of the major transformation products in steel, and forms the basis of many mathematical models which are based on physical principles, and which permit the calculation of overall microstructure as a function of chemical composition and processing.

\begin{tabular}{|c|}
\hline Comment \\
\hline Nucleation and growth reaction \\
\hline Plate shape \\
\hline IPS shape change with large shear \\
\hline Lattice correspondence during growth \\
\hline Co-operative growth of ferrite and cementite \\
\hline High dislocation density \\
\hline Necessarily has a glissile interface \\
\hline Always has an orientation within the Bain region \\
\hline Grows across austenite grain boundaries \\
\hline High interface mobility at low temperatures \\
\hline Acoustic emissions during transformation \\
\hline Reconstructive diffusion during growth \\
\hline Bulk redistribution of $X$ atoms during growth \\
\hline Displacive transformation mechanism \\
\hline Reconstructive transformation mechanism \\
\hline Diffusionless nucleation \\
\hline Only carbon diffuses during nucleation \\
\hline Reconstructive diffusion during nucleation \\
\hline Often nucleates intragranularly on defects \\
\hline Diffusionless growth \\
\hline Local equilibrium at interface during growth \\
\hline Local paraequilibrium at interface during growth \\
\hline Diffusion of carbon during transformation \\
\hline Carbon diffusion-controlled growth \\
\hline Incomplete reaction phenomenon \\
\hline
\end{tabular}

\begin{tabular}{|c|c|c|c|c|c|c|c|}
\hline 1 & $\alpha_{l b}$ & $\alpha_{u b}$ & $\alpha_{a}$ & $\alpha_{w}$ & $\alpha$ & $\alpha_{i}$ & $P$ \\
\hline & $=$ & $=$ & $=$ & $=$ & $=$ & $=$ & $=$ \\
\hline & $=$ & $=$ & $=$ & $=$ & $\neq$ & $\neq$ & $\neq$ \\
\hline & $=$ & $=$ & $=$ & $=$ & $\neq$ & $\neq$ & $\neq$ \\
\hline & $=$ & $=$ & $=$ & $\neq$ & $\neq$ & $\neq$ & $\neq$ \\
\hline & $\neq$ & $\neq$ & $\neq$ & $\neq$ & $\neq$ & $\neq$ & $=$ \\
\hline$=$ & $=$ & $=$ & $=$ & $\bullet$ & $\neq$ & $\neq$ & $\neq$ \\
\hline$=$ & $=$ & $=$ & $=$ & $=$ & $\neq$ & $\neq$ & $\neq$ \\
\hline$=$ & $=$ & $=$ & $=$ & $=$ & $\neq$ & $\neq$ & $\neq$ \\
\hline & $\neq$ & $\neq$ & $\neq$ & $\neq$ & $=$ & $=$ & $=$ \\
\hline$=$ & $=$ & $=$ & $=$ & $=$ & $\neq$ & $\neq$ & $\neq$ \\
\hline 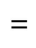 & $=$ & $=$ & & & & & \\
\hline & $\neq$ & $\neq$ & $\neq$ & $\neq$ & $=$ & $=$ & $=$ \\
\hline 7 & $\neq$ & $\neq$ & $\neq$ & $\neq$ & • & • & $\bullet$ \\
\hline & $=$ & $=$ & $=$ & $=$ & $\neq$ & $\neq$ & $\neq$ \\
\hline & $\neq$ & $\neq$ & $\neq$ & $\neq$ & $=$ & $=$ & $=$ \\
\hline & $\neq$ & $\neq$ & $\neq$ & $\neq$ & $\neq$ & $\neq$ & $\neq$ \\
\hline & $=$ & $=$ & $=$ & $=$ & $\neq$ & $\neq$ & $\neq$ \\
\hline 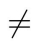 & $\neq$ & $\neq$ & $\neq$ & $\neq$ & $=$ & $=$ & $=$ \\
\hline & $\neq$ & $\neq$ & $=$ & $\neq$ & $\neq$ & $=$ & $\neq$ \\
\hline & $=$ & $=$ & $=$ & $\neq$ & $\neq$ & $\neq$ & $\neq$ \\
\hline & $\neq$ & $\neq$ & $\neq$ & $\neq$ & $\bullet$ & $\bullet$ & $\bullet$ \\
\hline & $\neq$ & $\neq$ & $\neq$ & $=$ & $\bullet$ & $\bullet$ & $\neq$ \\
\hline & $\neq$ & $\neq$ & $\neq$ & $=$ & $=$ & $=$ & $=$ \\
\hline & $\neq$ & $\neq$ & $\neq$ & $=$ & • & • & $\bullet$ \\
\hline & $=$ & $=$ & $=$ & $\neq$ & $\neq$ & $\neq$ & $\neq$ \\
\hline
\end{tabular}

Table 2: Key transformation characteristics in steels. Martensite $\alpha^{\prime}$, lower bainite $\alpha_{\mathrm{lb}}$, upper bainite $\alpha_{\mathrm{ub}}$, acicular ferrite $\alpha_{\mathrm{a}}$, Widmanstaetten ferrite $\alpha_{\mathrm{w}}$, allotriomorphic ferrite $\alpha$, idiomorphic ferrite $\alpha_{\mathrm{i}}$, pearlite $P$, substitutional solutes $\mathrm{X}$. Consistency of a comment with the transformation is indicated by $=$, inconsistency by $\neq$. A bullet identifies cases where the comment is only sometimes consistent with the transformation. The term parent $\gamma$ implies the $\gamma$ grain from which the product phase grows. Adapted from [Bhadeshia, Christian 1990]. 


\section{Acknowledgement}

I am especially grateful to all who have been so generous in selflessly organising this event, in particular, Professor Hans-Werner Zoch, Dr Michael Lohrmann and the staff of the AWT.

\section{References}

Arif, T. T., Qin, R., 2014. A phase-field model for the formation of martensite and bainite. Advanced Materials Research 922, 31-36.

Arif, T. T., Qin, R. S., 2013. A phase-field model for bainitic transformation. Computational Materials Science 77, 230-235.

Bhadeshia, H. K. D. H., 1983. Considerations of solute drag in relation to transformations in steels. Journal of Material Science 18, 1473-1481.

Bhadeshia, H. K. D. H., 1984. Solute-drag, kinetics and the mechanism of the bainite transformation. In: Marder, A. R., Goldstein, J. I. (Eds.), Phase Transformations in Ferrous Alloys. TMS-AIME, Ohio, USA, pp. 335-340.

Bhadeshia, H. K. D. H., 1985. Di usional formation of ferrite in iron and its alloys. Progress in Materials Science 29, 321-386.

Bhadeshia, H. K. D. H., 2015a. Anomalies in carbon concentration determinations from nanostructured bainite. Materials Science and Technology 31, 758-763.

Bhadeshia, H. K. D. H., 2015b. Bainite in steels: theory and practice, 3rd Edition. Maney Publishing, Leeds, U.K.

Bhadeshia, H. K. D. H., 2016. Some di culties in the theory of di usion-controlled growth in substitutionally alloyed steels. Current Opinion in Solid State and Materials Science 20, 396-400.

Bhadeshia, H. K. D. H., 2017. Geometry of Crystals, Polycrystals, and Phase Transformations. CRC press, ISBN 9781138070783 , Florida, USA.

Bhadeshia, H. K. D. H., Christian, J. W., 1990. The bainite transformation in steels. Metallurgical \& Materials Transactions A 21A, 767-797.

Bhadeshia, H. K. D. H., Edmonds, D. V., 1980. The mechanism of bainite formation in steels. Acta Metallurgica 28, 1265-1273.

Bhadeshia, H. K. D. H., Honeycombe, R. W. K., 2017. Steels: Microstructure and Properties, 4th Edition. Elsevier.

Bilby, B. A., 1955. Types of dislocation source. In: Bristol Conference Report on Defects in Crystalline Solids. The Physical Society, London, U.K., pp. 124-133.

Borgenstam, A., Engstron, A., Hoglund, L., Agren, J., 2000. DICTRA, a tool for simulation of di usional transformations in alloys. Journal of Phase Equilibria 21, 269-280.

Caballero, F. G., Miller, M., Yen, H. W., Jimenez, J. A., Mateo, C. G., Rivas, L. M., Yang, J. R., 2014. Carbon supersaturation and tetragonal bainitic ferrite in nanocrystalline bainitic steels, TMS2014, 143rd Annual Meeting and Exhibition, San Diego, USA.

Caballero, F. G., Miller, M. K., Garcia-Mateo, C., 2011. Atom probe tomography analysis of precipitation during tempering of a nanostructured bainitic steel. Metallurgical \& Materials Transactions A 42, 3660-3668.

Caballero, F. G., Miller, M. K., Garcia-Mateo, C., Cornide, J., 2013. New experimental evidence of the di usionless transformation nature of bainite. Journal of Alloys and Compounds 577, S626-S630.

Chatterjee, S., Wang, H. S., Yang, J. R., Bhadeshia, H. K. D. H., 2006. Mechanical stabilisation of austenite. Materials Science and Technology 22, 641-644.

Christian, J. W., 1958. Accommodation strains in martensite formation, the use of the dilatation parameter. Acta Metallurgica 6, 377-379.

Coates, D. E., 1972. Di usion controlled precipitate growth in ternary systems I. Metallurgical Transactions 3, 1203-1212.

Coates, D. E., 1973. Precipitate growth kinetics for Fe-C-X alloys. Metallurgical Transactions 4, 395-396.

Colbeck, E. W., Rait, J. R., 1952. Creep-resisting ferritic steels. Tech. Rep. Special report 43, Iron and Steel Institute, London, U.K.

Davenport, E. S., Bain, E. C., 1930. Transformation of austenite at constant subcritical temperatures. Trans. Am. Inst. Min. Metall. Engng. 90, 117-154.

Ehrenfest, P., 1933. Phasenumwandlungen im ueblichen und erweiterten sinn, classifiziert nach dem 
entsprechenden sigularitaeten des thermodynamischen potentiales.

Verhandelingen der Koninklijke Akademie van Wetenschappen (Amsterdam) 36, 153-157.

Frank, F. C., 1950. Report of the pittsburgh symposium. In: Symposium on the Plastic Deformation of Crystalline Solids. O ce of Naval Research, Pittsburgh, USA, p. 150.

Hilliard, J. E., 1970. Spinodal decomposition. In: Zackay, V. F., Aaronson, H. I. (Eds.), Phase Transformations. ASM International, Metals Park, Ohio, USA, pp. 497-560.

Hulme-Smith, C. N., Lonardelli, I., Dippel, A. C., Bhadeshia, H. K. D. H., 2013. Experimental evidence for non-cubic bainitic ferrite. Scripta Materialia 69, 409-412.

Ko, T., Cottrell, S. A., 1952. The formation of bainite. Journal of the Iron and Steel Institute 172, 307-313.

Machlin, E. S., Cohen, M., 1951. Burst phenomenon in the martensitic transformation. Trans. Metall. Soc. AIME 191, 746-754.

Olson, G. B., Cohen, M., 1979. Interphase boundary dislocations and the concept of coherency. Acta Metallurgica 27, 1907-1918.

Ramazani, A., Li, Y., Mukherjee, K., Prahl, U., Bleck, W., A. Abdurakhmanov, M. S., Reisgen, U., 2013. Microstructure evolution simulation in hot rolled DP600 steel during gas metal arc welding. Computational Materials Science 68, 107-116.

Shipway, P. H., Bhadeshia, H. K. D. H., 1995. Mechanical stabilisation of bainite. Materials Science and Technology $11,1116-1128$.

Song, W., Prahl, U., Bleck, W., Mukherjee, K., 2011. Phase field simulations of bainitic phase transformations in $100 \mathrm{Cr} 6$. In: Materials fabrication, properties, charaterisation and modelling. J. Wiley \& Sons, New Jersey, USA, pp. 417-425.

Swallow, E., Bhadeshia, H. K. D. H., 1996. High resolution observations of displacements caused by bainitic transformation. Materials Science and Technology 12, 121-125.

Zhang, F. C., Wang, T. S., Zhang, P., Zhang, C. L., Lv, B., Zhang, M., Zhang, Y. Z., 2008. A novel method for the development of a low-temperature bainitic microstructure in the surface layer of low-carbon steel. Scripta Materialia 59, 294-296.

Zhu, Z., Han, J., Li, H., Lu, C., 2016. High temperature processed high Nb X80 steel with excellent heat-a ected zone toughness. Materials Letters 163, 171-174. 